\title{
하지 정맥류의 최신지견 A Recent Overview of Varicose Vein in the Legs
}

\section{조 광 조}

동아의대 동아대병원 흉부외과

부산 동대신동 3가 1번지

Kwang Jo Cho, M.D.

Department of Thoracic and Cardiovascular Surgery

Dong A University College of Medicine \& Hospital

E-mail : gjcho@donga.ac.kr

\section{Abstract}

Vistaras

aricose vein is one of the ancient diseases, which has its evidence in Greek sculpture. Nowadays varicose vein has become a popular disease because of the media, so that many people want to treat their varicose vein and many medical doctors from a variety of fields seek a varicose clinic, accordingly. Since the introduction of the great saphenous vein stripping, the treatment of varicose vein has not been changed very much for about 100 years. Recently, however, many doctors in the outpatient varicose clinic prefer less invasive treatment and some innovative techniques that have become available recently. Endovascular treatment or transilluminated powered phlebectomy is one of them. Some dermatologists try to treat all kinds of varicose vein with sclerotherapy. But the long-term results of the treatment reveal that the gold standard of the treatment of typical varicose vein is a groin -to-knee inversion stripping of the great saphenous vein with stab avulsion of the varicose cluster. The application of the color Doppler duplex ultrasonogram to the leg vein has made it possible to evaluate the reflux of axial veins and perforator veins more thoroughly and less invasively. Therefore ultrasonography is the method of choice for the diagnosis of varicose vein preoperatively and postoperative follow-up studies for recurrent cases. The recurrence of varicose vein after treatment is mostly from the remnant reflux in the saphenofemoral junction and its tributary. Thus more meticulous treatment of the tributaries of saphenofemoral junction is needed.

\section{Keywords : Varicose vein}

핵 심 용 어 : 하지 정맥류

\section{서 론}

하지정맥류는 매우 흔한 질환이며 고대로부터 알려진 오래된 질환이다. 그러나 그 치료법은 오랜기간 동안 큰 변화가 없었다. 이는 특별히 치명 적인 합병증을 초래하지도 않으며, 또한 정맥은 관찰하고 측정하기 어려 운 부분이므로 정맥에 대한 병태생리 의 이해와 의학적 관심이 최근까지 적었기 때문이었다(1). 1900년대 초 개발된 대복재정맥발거술과 경화요 법이 주된 치료법으로 백여년간 큰 변화가 없다가(2) 최근에야 생활의 질이 향상됨에 따라 정맥류 치료에 관심이 모아지며 기존 치료법의 단점 을 보완하고자 하는 치료법이 점차 개발되어 소개되고 있다. 최근 우리 나라에서는 대중매체의 관심이 받아 정맥류에 대한 일반인들의 관심이 더 욱 높아지고 있어 개업가 여러 분야 의 많은 의사들이 정맥류 치료 클리 
닉을 열고 있다. 이에 지금까지의 학계에 정설로 인정되 고 있는 정맥류에 대한 의학적 지식들을 살펴 정리하고자 한다.

\section{정의 및 병태생리}

대부분의 학자들이 선호하는 정맥류의 일반적인 정의 는 Arnoldi(3)의 정의로 "어떤 형태로든지 정맥이 늘어 나고, 길어지며, 구부러진 것”이다. 이는 모세혈관확장증 (telangiectases), 망상진피정맥확장증(reticular vein), 및 정맥류(varicose vein)를 모두 통합하는 정의다. 그러 나 늘어난다는 것은 정맥압의 증가를 반영한 정의로서 판 막기능의 이상을 표현하는 데는 제한이 있다. Dodd와 Cockett(4)는 정맥류를 "정맥으로서의 기능을 영구적으 로 잃은 정맥"이라고 정의하여 병리적 인과를 표현하였 다. 정맥류를 크기와 부위별로 세분하여 정의하면, 모세 혈관확장증은 진피 내 정맥이 영구적으로 늘어난 것으로 직경이 $1 \mathrm{~mm}$ 이내인 것을 말하며, 망상진피확장증은 진 피 내 정맥이 영구적으로 늘어난 것으로 직경이 1 에서 $3 \mathrm{~mm}$ 사이인 것을 말하며, 정맥류는 피하 정맥이 영구적 으로 늘어난 것으로 직경이 $3 \mathrm{~mm}$ 이상인 것을 말한다(5).

하지의 정맥은 근막 아래 위치하는 심부정맥과 피하에 존재하는 표재성 정맥, 그리고 그 사이를 연결시켜 표재 성정맥에서 심부정맥으로 흘러가도록 판막이 생성되어 있는 관통정맥으로 이루어져 있다. 하지 표재성 정맥 중 가장 크고 긴 정맥이 대복재정맥인데, 발등의 정맥궁에서 시작되어 발목 내과의 앞쪽으로 올라가 장단지 내전측으 로 지나 무릎의 내후측으로 허벅지 내측으로 지나가 서혜 부에서 심부정맥인 대퇴정맥에 연결된다. 이 대복재정맥 은 다른 표재성 정맥보다 피하조직 깊은 층에 있어 피하 지방층을 가르는 표재성 근막(superficial fascia 혹은 saphenous fascia) 아래에 있다. 장단지 후방에 발목 외 과에서 시작되어 슬와정맥으로 유입되는 소복재정맥과 함께 이들 대소복재정맥을 축정맥(axial vein)이라 한다. 정맥류는 심부정맥압의 역류에 의한 표재성 정맥 고혈압 에 의해 유발된다. 가장 중요한 역류 부위는 축정맥 연결 부와 관통정맥이다. 이 곳의 판막 기능의 부전으로 표재 성 정맥 고혈압이 유발되고 결국 정맥류가 형성되게 된 다. 축정맥의 역류압은 중력역류로 인한 혈액 기둥의 정 수압(hydrostatic pressure)이며 서있는 정상 성인에서 약 $100 \mathrm{mmHg}$ 정도가 발에 전달된다(1). 관통정맥의 역 류는 주로 하지 근육 구획 내 근수축압을 전달시키는데, 이는 유체역학압(hydrodynamic pressure)이며 150에 서 $300 \mathrm{mmHg}$ 에 달한다(6). 한 조사에 의하면 축정맥의 중력역류가 동반된 전형적인 정맥류는 $71 \%$ 정도였는데 그 수가 164 다리에서 있었고 그 중 147 다리는 대복재정 맥역류, 나머지 17 다리는 소복재정맥역류에 의한 것이 라 하였고, 순수 관통정맥역류에 의해서만 발생한 비전형 적 정맥류는 $22 \%$ 라고 하였다(7).

\section{역학 및 원인}

정확한 유병률과 발병률에 대한 것은 논란의 여지가 있 지만 일반적으로 정맥류는 전 여성의 40 60\%, 전 남성 의 15 30\% 정도에서 있다고 한다(8). 나이가 들수록 유 병률은 증가하여 한 보고에 의하면 노인에서 5 배가 더 많 다고 한다(9). 정맥류의 유전적 소인은 매우 높은 것으로 알려져 있어 가족적 소인이 인정되는 정맥류는 $43 \%$ 에서 $90 \%$ 까지로 보고되고 있다(10). 한 연구에 의하면 양친 이 모두 정맥류를 가질 경우 자녀는 $90 \%$ 에서 정맥류를 가지고, 한쪽 부모가 가지면 남아는 $25 \%$, 여아는 $62 \%$ 에 서 정맥류가 발생되며, 양 부모가 모두 정맥류가 없을 경 
우 정맥류를 가질 확률은 $20 \%$ 라 한다(11). 정맥류는 임 신 기간중에 처음 발생하는 경우가 많고 또한 임신 기간 동안 심해지는 것으로 알려져 있는데 이는 태반이 정맥 환 류를 막기 때문이라 생각할 수도 있지만 자궁이 커지기 전 인 임신 첫 3개월 동안 정맥류는 잘 발생하므로 단순히 기 계적인 원인 이외에도 임신은 정맥류 발생에 기여하는 것 으로 생각된다. 아직까지 인과관계가 명확히 밝혀지진 않 았지만 프로게스테론은 자궁과 혈관 평활근의 수축을 같 이 억제하므로 정맥류 발현에 영향을 주리라 생각된다(8). 임신이나 유전 외에도 정맥류를 일으키는 소인으로는 비 만, 장시간 서서 일하는 직업, 오래 앉아 일하는 직업, 변 비, 운동부족, 꽉 끼는 의류, 높은 좌변기, 흡연, 피임약 등 을 들 수 있다(8). 이들은 하지 정맥으로 연결되는 정수압 을 증가시키는 것과 관련있는 요소들이라 하겠다.

그러나 최근 발표되는 여러 연구에 의하면 정맥류를 일 으키는 기전을 단지 정맥압의 상승에 두기에는 부족한 면 이 있다. 혈관외과에서 흔히 경험하는 것인데, 대복재정 맥을 사용한 동맥우회로수술 후에는 정맥 도관이 늘어나 는 것이 아니라 두꺼워진다(동맥화). 또한 대복재정맥의 판막 기능을 제거한 in situ 도관을 사용하더라도 정맥류 가 형성되는 경우는 드물다. 그러므로 정맥류는 정맥벽 자체의 기질적 이상이 정맥압 상승요인과 맞물려서 발생 하는 것이라 생각할 수 있다. 정맥류가 유발된 대복재정 맥은 서혜부에서 무릎까지 판막이 $50 \%$ 에서 소실되어 있 으며 혈관경으로 관찰할 경우 대복재정맥의 판막은 천공, 분리, 위축되어 있다고 한다(12). 정맥류가 발생된 정맥벽 의 현미경적 소견은 내피세포는 공포가 생기게 되고 핵은 농축되어 있으며, 중층은 얇아지고 그 안의 평활근은 섬유 화 변성이 일어나 교원질(collagen)로 대치되어 있으며 교 원질섬유도 부종과 나선형 분리가 되어 있는데 이들 변성 은 일정하지 않아 정맥벽의 어느 부분은 두꺼운 섬유화가
되어 있고 어느 부분은 얇아져 늘어나 있다고 한다(10). 정맥류를 일으킨 정맥벽은 생리적으로도 이상을 보여 일 산화질소가스에 반응하여 혈관을 늘리는 내피의 기능이 정상보다 $86 \%$ 나 떨어져 있으며, endothelin, $\mathrm{KCl}$, norepinephrin, serotonin, histamine, 수동적 견인 등의 자 극에 반응하여 수축하는 혈관 평활근의 기능이 떨어져 있 는 등 정맥벽의 내피 및 중층 평활근의 기능이 다 저하되 어 있다(13).

정맥벽의 전단력 및 압력의 비정상적인 증가는 염증을 일으키는 유전자 생성을 증가시킨다. 이는 염증 매개체를 유리시켜 결국 정맥벽에 굴러다니는 단핵구(monocyte) 들이 판막과 벽에 침투하게 한다(8). 한 연구에 의하면 CD-64 monoclonal Ab staining상 대식구(macrophage)가 된 단핵구는 정맥류 대복재정맥 근위부의 정맥 벽, 특히 판막기저부에 다량 발견되고 그 세포벽에는 ICAM-1이 발현되어 있다고 한다(14). 이 단핵구에서 유리된 독성물질은 정맥벽을 약화시키고 판막 파괴를 유 발하는 것으로 생각된다.

\section{임상상 및 치료의 적응}

정맥류의 주된 임상증상은 표재성 정맥이 붉어짐으로 인한 외관상 불편함, 경우에 따라 동반되는 통증, 정맥부 전이 진행됨에 따라 말기에 발생되는 피부 병변 등이다. 표재성 정맥 중 가장 먼저 붉어지는 곳은 장단지의 상부 내측에 Boyd 관통정맥과 연결된 표재성 정맥분지이다. 다음으로 잘 발생되는 곳은 허벅지 하부 내측에 있는 Dodd 및 Hunter 관통정맥 연 분지들인데 이들은 대복재 정맥과 연결되어 있는 관통정맥들이다(6). 정맥이 튀어 나오는 것은 오랜기간 서 있을수록 심해지고 여성에서는 월경시나 임신시 심해진다. 
정맥류에 의한 통증은 병소 정맥 주위의 감각신경을 늘 어난 정맥이 누르는 것과 관련해서 발생하는 증상이다. 통증의 강도는 정맥류의 길이나 크기와 무관하게 발생한 다. 통증은 가장 흔한 증상이기는 하지만 다 발생하는 증 상은 아니다. 그 외 증상으로는 다리가 쉽게 피곤해지며 무거워지는 것 등이다.

정맥류로 인해 정맥부전이 발생하기 시작하면 가장 먼 저 일어나는 증상은 부종이다. 발목 주위 신발에 끼이는 부 위에 자국이 발생하는 것으로 시작하는 부종은 정맥부종이 진행됨에 따라 장단지로 진행된다. 림프부종과 달리 중족 골 근처는 초기에는 잘 붓지 않는다. 또한 초기에는 누르면 들어가지만 말기가 되면 피하조직 섬유화가 일어나 들어가 지 않게 된다. 그러나 이런 심한 부종은 잘 일어나지 않고 대부분 다리를 들거나 누워서 쉬면 쉽게 소실되게 된다.

만성 정맥부전의 마지막 표적 장기는 피부다. 혈철소 (hemosiderin)의 축적으로 피부변색이 일어나고 더 진 행되면 염증 물질이 축적되어 급성 염증, 만성 염증, 궤 양, 지방성 진피 경화(lipodermatosclerosis) 및 피부 위 축(atrophie blanche) 등이 발목 내측에 잘 유발된다. 그 외에도 늘어난 표재성 정맥류에 혈전이 형성되고 정맥염 을 일으키거나 정맥압이 증가되어 위축된 피부로 출혈하 는 경우도 일어날 수 있다. 그러나 이러한 합병증들은 정 맥류에서 흔하게 일어나지는 않으며 오래 진행된 경우에 발생한다.

치료는 이러한 임상적인 증상이 있는 경우 모두 적응이 된다. 즉 외관상 불편을 느끼거나, 통증, 다리가 무겁거나 쉽게 피곤을 느낄 때, 표재성 정맥염이나 출혈, 피부병변 을 유발하는 정맥 부전이 병발될 때 등이다. 경화요법보 다 수술(phlebectomy)을 고려하게 하는 상황은 축정맥 역류, 특히 대복재정맥역류와 관통정맥부전으로 인한 큰 정맥류 형성이다(15).

\section{진단과 치료}

정맥류는 외부로 들어나는 질환이므로 진단에 어려움 은 없다. 그러나 치료를 계획하는 경우 좀 더 많은 정보가 필요하게 된다. 초음파의 발전은 정맥부전의 진단에 획기 적인 발전을 가져왔다. 도플러 이중 칼라 초음파 검사는 대소복재정맥의 역류 여부 및 그 정도에 대한 정확한 정 보를 제공하며 각 부위에 따른 관통정맥의 역류에 대한 정보도 얻을 수 있으므로 실질상으로 초음파는 정맥조영 술 및 다른 침습적인 검사를 대신하게 되었다. 초음파 검 사는 비침습적이고 반복이 용이하고 저렴하며 쉽게 배울 수 있다. 초음파가 개발되기 전에는 정맥류의 표준치료는 대복재정맥을 서혜부로부터 발목까지 완전히 발거하는 전통적인 것이었다. 이는 중력 역류와 관통정맥 역류를 동시에 제거하는 효과적인 방법으로 이 경우 특별한 진단 을 요하지는 않았다. 그런데 이 수기는 복재정맥 주위로 지나가는 감각신경인 saphenous nerve의 손상을 유발 할 수 있고, 또한 무릎 아래 관통정맥의 대부분인 $\mathrm{Co}^{-}$ ckett 관통정맥은 대복재정맥의 분지인 후궁동맥 (Posterior arch vein)에 주로 연결되어 있어서 무릎 아 래 대복재정맥의 제거는 관통정맥 역류의 제거라는 원래 의 목적에 부합되지 못하므로 이제는 더 이상 무릎 아래 대복재정맥을 발거하지 않게 되었다. 또한 약 $30 \%$ 경우 복재정맥의 역류가 없는 비전형적 정맥류이거나 소복재 정맥역류가 동반되는 정맥류이므로(7) 이에 대한 정보가 필요하게 되었다. 초음파가 제공하는 해부학적 정보는 치 료 선택은 물론 치료 안내 지표로도 유용하므로 이제 정 맥류 치료 전 및 치료중 초음파 검사는 필수적인 도구가 되었다(8)

전형적인 정맥류는 축정맥을 통한 중력역류를 제거하 고 관통정맥을 통한 근막내압 역류를 제거하는 것이 치료 
원칙인데 이를 영구적이고, 합병증을 최소화하며, 미용상 가장 좋은 결과를 가져오게 하는 치료법이 가장 이상적인 것이다. 과거와 달리 최근에는 가능하면 전신마취를 피하 고, 최소침습을 주며, 입원 없이 최소의 시간으로 시행할 수 있는 치료법이 선호되고 있다.

중력역류의 제거를 위한 방법은 대복재정맥의 서혜부 로부터 무릎까지 inversion technique으로 하향 발거하 는 것이 현재의 표준치료법이다. 상기했듯이 정맥류가 발 생한 경우 허벅지에서 대복재정맥의 판막이 부실하므로 (12) 무릎까지 제거기(stripper)의 통과가 용이하다. 서 혜부 절개로 복재대퇴정맥연결부에서 복재정맥을 분리 결찰한 다음 Codman stripper를 대복재정맥에 삽입하 여 무릎까지 통과시킨 다음 무릎에서 작은 절개로 제거기 를 뽑아내어 당겨서 정맥을 안으로 뒤집어 위로부터 아래 로 뽑아내는 수술법이다. 소복재정맥의 발거는 해부학적 변이가 심하기 때문에 반드시 초음파로 심부정맥과 연결 된 부위 및 역류 범위를 확인하고 발거해야 한다(6). 한 때 대복재정맥을 보존시켜 동맥우회로술 도관으로 사용 할 목적으로 복재대퇴정맥 연결부를 결찰 분리시켜 중력 역류를 제거하려는 시도가 있었지만 이 방법은 결국 복재 정맥을 보존하는 데는 성공했지만 중력역류를 제거하는 데는 실패하였다(16). 복재정맥결찰 결과 근위 $8 \sim 10 \mathrm{~cm}$ 만 막혔다고 하며(17) 결찰 10 개월 후에도 복재대정맥의 $78 \%$ 는 완전히 열려 있었으며, $15 \%$ 는 $10 \mathrm{~cm}$ 이하로 막혔 고 $7 \%$ 에서만 좀 더 길게 막혔다고 한다(18). 또한 다른 보고에 의하면 복재정맥결찰을 한 52 다리 중 24 다리는 여전히 역류하고 있었다고 한다(19). 결국 복재정맥결찰 은 특별한 경우가 아니면 해서는 안된다.

수술로 인한 침습을 줄이기 위해 최근에는 Radiofrequency나 Laser로 복재대정맥 안을 태워서 막는 정 맥 내 치료법이 개발되어 많이 사용되고 있다. 지금까지
알려진 바로는 술후 $1 \sim 3$ 년 동안 일반 수술과 동일한 효 과를 보인다고 하며(20), 수술보다 환자가 훨씬 편하게 느낀다고 보고되고 있다(21). Radiofrequency와 Laser 의 효과를 비교한 연구에서는 Radiofrequency가 더 잘 막았고 재발도 적었다(6). 이 치료법 시행 후 대복재정맥 을 초음파로 주의깊게 관찰한 결과 복재정맥 자체가 막히 고 쪼그라들어 있었지만 복재대퇴정맥연결부 주위에 연 결된 분지는 보존되어 있었다(22). 정맥 내 치료시 복재 정맥을 결찰 분리한 군과 안한 군을 비교한 결과 재발에 차이가 없었다(91). 부작용으로는 재개존, 허벅지 감각이 상, 피부 화상, 심부정맥혈전 혹은 전색증 등이 있다(10). 그러나 이 수기로 치료된 정맥류의 장기재발 정도를 알기 위해서는 좀 더 장기간의 추적연구가 필요할 것이다.

관통정맥을 통한 역류의 제거는 보행 정맥 제거술 (ambulatory phlebectomy)로 잘 치료할 수 있다. 관통 정맥을 근막 근처에서 절단하는 것은 필요하지도 않고 미 용상 좋지 않다. 정맥류가 발달된 부위 피부를 $1 \sim 2 \mathrm{~mm}$ 절개하고 Muller hook이나 겸자로 정맥류를 밖으로 들 어내어 분리한 다음 가능한 깊이 뽑아낸다. 정맥 제거 후 다리를 들거나 누르면 잘 지혈되며 절개부는 tape이나 흡수봉합사로 단순 봉합한다. 축정맥역류가 없는 비전형 적 정맥류는 이 수기만으로 충분하지만 전형적인 정맥류 에서 복재정맥발거를 같이 해야 하는 경우는 말초 정맥에 고혈압을 일으키므로 발거 전에 정맥 제거술을 시행한다 (8). 그러나 이 방법은 지표 없이 작은 절개로 시행되는 술식으로 역류 부위를 모두 제거하지 못할 수 있어 잔존 정맥류를 남길 수 있다. 최근에는 $\operatorname{Spitz}(24)$ 등이 광투시 정맥흡입술을 개발하여 좀 더 간편하게 이런 문제를 해결 하고자 하였다. 이 수기는 광원과 희석마취수액을 주입할 수 있는 투시관과 전동으로 돌아가는 원통형 칼을 끝에 부착한 흡입분쇄관으로 구성된 장비를 통해 정맥류 덩이 
의 그림자를 보면서 직접 흡입분쇄하는 방법으로 적은 소 절개를 통해 넓은 범위의 정맥류를 짧은 시간에 완전히 제거할 수 있는 장점이 있어 짧은 회복기간, 미용상 탁월 한 효과 및 적은 합병증 등의 효과를 얻을 수 있다. 단점 은 수기에 익숙해질 때까지 약간의 훈련이 필요하다는 것 이다. 합병증으로는 봉와직염, 멍, 부종 등이 $6.8 \%$ 에서 발생된다고 하는데(10), 저자의 경험으로는 118 다리에 서 시술한 결과 2 명에서 봉와직염이 발생되었었다(25).

경화요법은 정맥류 치료에 중요한 부분이지만 수술요 법을 대치하는 것으로 생각해서는 안되고 추가할 수 있는 요법으로 생각해야 한다. 이는 모든 정맥은 경화시킬 수 있지만 정맥고혈압 치료가 필요한 큰 정맥은 재개통되기 마련이기 때문이다. 경화요법은 $18.8 \%$ 의 중력역류 치료 의 실패율과 $43.8 \%$ 의 근막내압 역류 제거 실패율로 수술 보다 비효과적이라고 결론지어졌다(26). 그러므로 경화요 법을 시행하기 전에 심부정맥에서 표재성 정맥으로 역류 하는 모든 부위는 수술로 분리되어져야 한다(8). 경화요법 의 적응증은 모세혈관확장증, 망상진피정맥확장증 등 직 경이 $3 \mathrm{~mm}$ 이내의 정맥확장증, 비전형성 정맥류 중 비교 적 작은 것, 복재대정맥발거술 후 재발된 정맥류, 정맥류 수술 후 잔존하는 정맥류 등이 가장 적절한 대상이다.

정맥류 치료 후 재발하는 경우는 대부분 대복재정맥역 류의 잔존에 의한 것이라고 한다. 한 보고에는 122 재발 정맥류를 초음파 검사한 결과 $71.3 \%$ 가 대복재정맥과 연 결된 대퇴부 표재정맥에서 발생되었고(27), 또 다른 보고 에는 127 재발 정맥류 조사 결과 단일 부위 심부정맥역류 를 찾는 경우의 $58 \%$ 가 대복재대퇴정맥 연결부였다고 한 다(28). 즉 첫 수술시 대복재대퇴정맥 연결부 주위 분지 들의 좀 더 철저한 발거가 필요하다고 하겠다. 수술치료 에 대한 장기 재발 여부에 대한 보고들은 대개 5년 후 재 발은 약 $25 \%$ 안팎에서 보고되고 있고(29), 더 장기간
추적에 대한 한 보고에 의하면 대복재정맥을 서혜부에서 발목까지 발거한 후 34 년 뒤 재발률은 $60 \%$ 에 달했다고 한다(30).

\section{요 약}

하지정맥류는 심부정맥에서 표재정맥으로의 역류로 표 재정맥압이 상승하며 표재정맥의 기질적인 이상으로 인 해 늘어나고 길어지며 굽어진 표재정맥의 영구적 기능 장 애 상태다. 정맥류는 미용상 문제가 되기도 하며 정맥 부 전의 증상을 유발할 수도 있는데, 환자가 불편하다고 느 낀다면 치료를 해주어야 한다. 치료는 초음파 소견상 대 소복재정맥의 역류 여부와 늘어난 정맥의 부위를 정확히 진단하여 복재정맥의 역류가 없고 늘어난 정도가 $3 \mathrm{~mm}$ 이하로 작을 경우 경화요법을 적용할 수 있으나 대부분의 전형적인 정맥류는 대복재정맥을 서혜부에서 무릎까지 발거해서 중력역류에 의한 정수압 원천을 제거해 주고 정 맥제거술로 관통정맥 역류를 제거해 주는 것이 표준치료 이다. 최근에 개발된 정맥 내 Radifrequency나 Laser 치 료는 대복재정맥을 제거하는 데 효과적이나 장기 효과는 좀 더 많은 연구가 필요할 것이다. 정맥 제거는 광투시정 맥흡입술로 더욱 효과적으로 시행할 수 있게 되었다. 9

\section{참 고 문 헌}

1. Browse LN, Burnand KG, Thomas ML. Diseases of the veinspathology, diagnosis and treatment. London: Edward Arnold, 1988: $53-69$

2. John JB. Evaluation of varicose vein surgery. In: Advances in vascular surgery. vol 6. St Luis: Mosby, 1998: 81 - 91

3. Arnoldi CC. The aetiology of primary varicose veins. Dan. Med. 
Bull 1957; 4: $102-7$

4. Dodd $H$, Cockett FB. The pathology and surgery of the veins of the lower extremities. Edinburgh: Livingston, 1956: 3 - 8

5. Allegra C, Antignani PL, Bergan JJ, Carpentier PH, ColeridgeSmith P, Widmer MT, et al. The "C" of CEAP: Suggested definitions and refinements: An international union of phlebology conference of experts. J Vasc Surg 2003; 37: 129 - 31

6. Bergan JJ. Varicose veins: treatment by intervention including sclerotherapy. In: Rutherford RB. Vascular surgery. 6th ed. Philadelphia: Elsevier Saunders, 2005: 2251 - 67

7. Goren G, Yellin AE. Primary varicose veins: Topographic and hemodynamic correlations. J Cardiovasc Surg 1990; 31: 672 - 9

8. Bergen JJ. Etiology and surgical management of varicose veins. In: Hubson RW, Wilson SE, Veith FJ, ed. Vascular surgery-principles and practice. 3rd ed. New York: Marcel Dekker, Inc, 2004: 949 - 62

9. Madar G, Widmer L. Varicose veins and chronic venous insufficiency: disorder or disease? A critical epidemiological review. Vasa 1986; 15: 126 - 34

10. lafrati MD, O'Donnell TF Jr. Varicose vein. In: Ascher E, ed. Haimovici's vascular surgery. 5th ed. Massachusetts: Blackwell Publishing, 2004: 1058 - 72

11. Cornu - Thenard A, Boivin P, Baud JM. Importance of the familial factors in varicose disease. Clinical study of 134 families. J Dermatol Surg Oncol 1994; 20: 318 - 26

12. Van Cleef JF. A vein has a preferential axis of flattening. J Dermatol Surg Oncol 1993; 19: 468 - 70

13. Thulesius $\mathrm{O}$, Ugaily-Thulesius $\mathrm{L}$. The varicose saphenous vein, functional and ultrastructual studies, with special reference to smooth muscle. Phlebology 1988; 3: 89 - 95

14. Takase S, Schmid-Schonbein GW, Bergan JJ. Expression of adhesion molecules and cytokines on saphenous veins in chronic venous insufficiency. Ann Vasc Surg 2000; 14: 427 - 35

15. Neumann HAM. Ambulant minisurgical phlebectomy. J Dermatol Surg Oncol 1992; 18: 53 - 58

16. McMullin GM, Coleridge-Smith PD, Scurr JH. Objective assessment of high ligation without stripping the long saphenous vein. Br J Surg 1991; 78: 1139 - 43

17. Rutherford RB, Sawyer JD, Jones DN. The fate of residual saphenous vein after partial removal or ligation. J Vasc Surg $1990 ; 12: 422-28$

18. Friedell ML, Samson RH, Cohen MJ. High ligation of the greater saphenous vein for treatment of lower extremity varicosities: the fate of the vein and therapeutic results. Ann Vasc Surg 1992; 6: 5 - 8

19. McMullin GM, Coleridge-Smith PD, Scurr JH. Objective assessment of high ligation without stripping the long saphenous vein. Br J Surg 1991; 78: 1139 - 42

20. Kabnick LS, Merchant RF. Twelve - and 24-month followup after endovascular obliteration of saphenous reflux: A report from the multicenter register. J Phlebol 2001; 1: 17 - 23

21. Goldman MP. Closure of the greater saphenous vein with endoluminal radiofrequency thermal heating of the vein wall in combination with ambulatory phlebectomy: Preliminary 6month followup. Dermatol Surg 2000; 26: 105

22. Pichot O, Sessa C, Chandler JG, Nuta M, Perrin M. Role of duplex imaging in endovenous obliteration for primary venous insufficiency. J Endovasc Ther 2000; 7: 451 - 9

23. Chandler JG, Pichot O, Sessa C, Schuller-Petrovic S, Osse FJ, Bergan JJ. Defining the role of extended saphenofemoral junction ligation: A prostective comparative study. J Vasc Surg 2000; 32: $941-53$ 
24. Spitz G, Braxton J, Bergan JJ. Outpatient varicose vein surgery with transilluminated powered phlebectomy. Vasc Surg 2000; 34: 547 - 55

25. 조광조. 하지 정맥류에서 광투시정맥흡입술의 임상적 경험. 대한혈관외과학회지 2002; 18: 230 - 6

26. Belcaro G, Nicolaides AN, Ricci A, Dugall M, Errichi BM, Christopoulos D, et al. Endovascular sclerotherapy, surgery, and surgery plus sclerotherapy for superficial venous incompetence: A randomized 10-year followup trial: Final results. Angiology 2000; 5: 529 - 34

27. Thibault PK, Lewis WA, Recurrent varicose veins: Evaluation utilizing duplex venous imaging. J Dermatol Surg Oncol 1992;
18: $618-24$

28. Redwood NFW, Lambert D. Patterns of reflux in recurrent varicose veins assessed by duplex scanning. Br J Surg 1994; 81: $1450-1$

29. Derrhyhouse S, Davies B, Harradine K, Earnshaw JJ. Stripping the long saphenous vein reduces the rate of reoperation for recurrent varicose vein; five-year results of a randomized trial. J Vasc Surg 1999; 28: 589 - 92

30. Fischer R, Linde N, Duff C, Jeanneret C, Chandler JG, Seeber P. Late recurrent saphenofemoral junction reflux after ligation and stripping of the greater saphenous vein. J Vasc Surg 2001; 34: $236-40$

\section{Peer Reviewer Commentary}

\section{박 장 상 (가톨릭의대 외과)}

본 논문에는 하지정맥류의 기본적인 병인론, 임상증상은 물론 적절한 진단방법 및 치료방법에 관련하여 비교적 정확 하게 기술되어 있다.

필자가 강조한 바와 같이 진단방법 중 초음파 이중주사(Ultrasonic duplex scanning) 방법은 전 세계적으로 중요한 비침습적 진단방법으로 정착되었다. 기존의 진단방법인 정맥촬영술이 주로 해부학적 소견만을 인지할 수 있고 혈역 동적 소견은 확인하기 어려운 반면, 이중주사 방법은 두 가지 소견을 동시에 확인할 수 있다는 중요한 장점이 있기 때문이다.

치료방법 중 경화요법은 수술요법을 대체할 수는 없고 추가로 병용하는 요법임을 강조한 부분은 정확한 지적이라고 하겠다. 관통정맥의 기능부전을 진단하기 위한 기준이 아직 정확하게 설정되어 있지 못하다. 관통정맥의 기능부전을 해결하는 방법으로 근막하내시경적관통정맥차단술(Subfascial Endoscopic Perforator Surgery, SEPS)이 널리 인 정되고 있다. 하지정맥류 자체를 해결할 때 관통정맥의 기능부전을 동시에 해결할 것인지의 여부와 그 방법에 대하 여는 장기간의 연구가 더 필요하다고 사료된다. 